University of Nebraska - Lincoln

DigitalCommons@University of Nebraska - Lincoln

Faculty Publications from the Harold W. Manter Laboratory of Parasitology

4-1956

\title{
Studies on the Helminth Fauna of Alaska. XXVIII. The Description and Occurrence of Diphyllobothrium dalliae n. sp. (Cestoda)
}

Robert L. Rausch

Arctic Health Research Center, rausch@uw.edu

Follow this and additional works at: https://digitalcommons.unl.edu/parasitologyfacpubs

Part of the Parasitology Commons

Rausch, Robert L., "Studies on the Helminth Fauna of Alaska. XXVIII. The Description and Occurrence of Diphyllobothrium dalliae n. sp. (Cestoda)" (1956). Faculty Publications from the Harold W. Manter Laboratory of Parasitology. 373.

https://digitalcommons.unl.edu/parasitologyfacpubs/373

This Article is brought to you for free and open access by the Parasitology, Harold W. Manter Laboratory of at DigitalCommons@University of Nebraska - Lincoln. It has been accepted for inclusion in Faculty Publications from the Harold W. Manter Laboratory of Parasitology by an authorized administrator of DigitalCommons@University of Nebraska - Lincoln. 


\title{
STUDIES ON THE HELMINTH FAUNA OF ALASKA. XXVIII. THE DESCRIPTION AND OCCURRENCE OF DIPHYLLOBOTHRIUM DALLIAE N. SP. (CESTODA)
}

\author{
ROBERT L. RAUSCH \\ Artic Health Research Center, Public Health Service, U. S. Department of Health, \\ Education, and Welfare, Anchorage, Alaska
}

Plerocercoid larvae of Diphyllobothrium spp. occur commonly in various species of freshwater and anadromous fishes in Alaska. Several times in recent years the writer has observed a distinctive plerocercoid in the blackfish, Dallia pectoralis Bean, an abundant and economically important species in the Kuskokwim River region of western Alaska. This cestode was studied in detail during the summer and fall of 1955 , and has been found to represent an undescribed species, for which the name Diphyllobothrium dalliae n. sp. is proposed.

Most of the material studied was obtained from blackfish trapped at Napaskiak, on the lower Kuskokwim River. The fish were sent to the laboratory at Anchorage, where the larvae were removed. Adult cestodes were reared in glaucous-winged gulls, Larus glaucescens Naumann, which had been hatched in an incubator and maintained parasite-free, and in dogs. Thirty-three cestodes, 3-11 days old, were obtained from the experimentally infected animals.

For study in toto, the larval and adult cestodes were stained with Semichon's acetic carmine and cleared in terpineol. Sections were stained with hematoxylin eosin. Before fixation of the strobilae, eggs were removed from gravid segments; these were allowed to hatch to permit observations on the coracidium.

The description of the adult stage is based mainly upon 11-day-old strobilae from gulls.

\section{Diphyllobothrium dalliae n. sp. (Figs. 1-3)}

Diagnosis: Maximum strobilar length $264 \mathrm{~mm}$, with about 170 segments; maximum width, attained in gravid segments, up to $5 \mathrm{~mm}$. Anterior portion of strobila little attenuated, widening rapidly posterior to scolex. Early segments trapezoidal, much wider than long; later segments increase in length, and in some strobilae terminal segments are longer than wide. More typically, length/width ratio of late gravid segments is about 1:2.5. Scolex lanceolate, up to $2 \mathrm{~mm}$ long by about $750 \mu$ wide; neck very short. Common genital pore median, in anterior third of segment; surrounded by prominent papillae. Vagina runs from ovary directly to genital pore; its position superficial and ventral until just posterior to genital pore, there turning abruptly dorsad and extending nearly to dorsal surface of segment, then turning abruptly ventrad, paralleling cirrus sac, to empty in floor of genital atrium. Ovary, consisting of bilateral lobes connected at middle by narrow isthmus, situated near posterior margin of segment. Uterus becomes visible in first 10-20 segments. First part of uterus much convoluted; part containing mature eggs consists of 5-7 compact loops on each side of midline. Uterine loops 

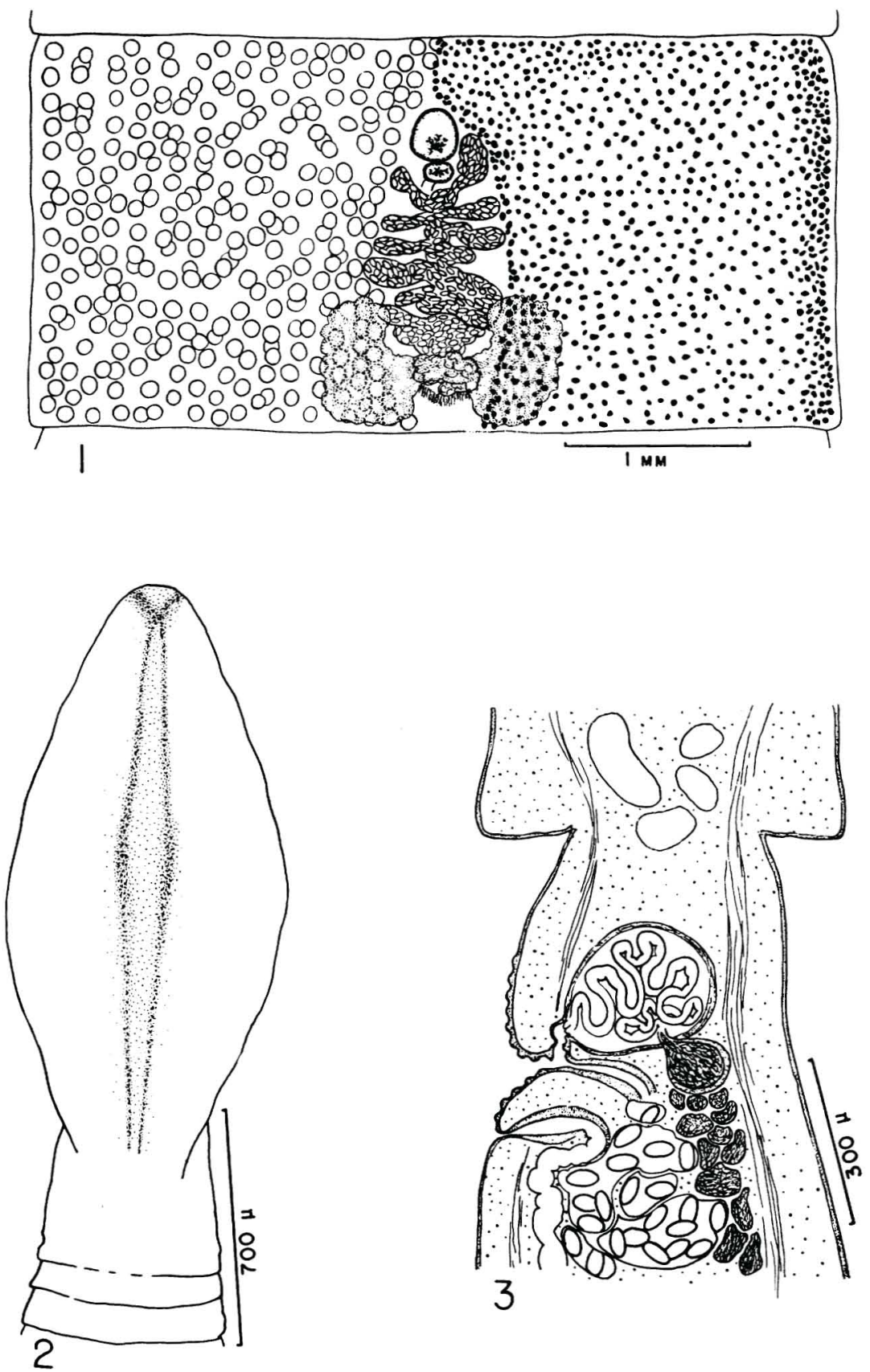

FIG. 1.7Diphyllobothrium dalliae n. sp., ventral view of gravid segment.

Fig. 2. $D$. dalliae n. sp., scolex.

Fig. 3. D. dalliae n. sp., sagittal section through gravid segment, showing relationships of genital ducts. 
do not extend anterior to cirrus sac. Uterine pore usually median, about $140 \mu$ posterior to genital pore. Eggs ovoid, 51-64 $\mu$ long by $40-44 \mu$ wide (av. $59 \times 42 \mu$ ); apical knob lacking. Vitellaria abundant; in lateral fields always joined at anterior margin and usually joined at posterior margin of segment; rarely overlap ends of uterine loops, but closely surround cirrus sac. Spherical to ovoid vitellaria average about $55 \mu$ in greatest diameter in gravid segments. Testes dorsal at two or three levels, about 600 per segment, measuring up to $130 \times 105 \mu$; distributed about as vitellaria, but less frequently confluent at posterior margin of segment. Cirrus sac pyriform, measuring up to $250 \times 215 \mu$, and opening into anterior floor of genital atrium. Spherical Propulsionblase external and posterior to end of cirrus sac; up to $130 \times 100 \mu$. Much coiled vas deferens dorsal.

Host: Adult cestode in experimentally infected glaucous-winged gull, Larus glaucescens Naumann; also in domestic dog.

Habitat: Small intestine of host.

Type locality: Napaskiak, lower Kuskokwim River, Alaska (origin of larvae).

Type: Slides bearing an entire strobila have been deposited in the Helminthological Collection of the U. S. National Museum, No. 38117.

Plerocercoid larva (Figs. 4-9)

Diagnosis: Body lanceolate, much flattened, tapering both ways from near middle (living material). Maximum length $32 \mathrm{~mm}$; up to $4 \mathrm{~mm}$ wide and about $500 \mu$ thick. Scolex evaginated, abruptly set off from body in dorso-ventral view; up to $1 \mathrm{~mm}$ long by $575 \mu$ wide (lateral view). Scolex lanceolate in lateral view, acuminate in dorso-ventral view; bothria extend full length of scolex, their posterior margins extending backward over first part of body. Cuticular folds resemble segmentation in contracted specimens. Integument, including that of scolex, covered by densely set bristles about $8 \mu$ long. Cuticle heavy, $8-15 \mu$ thick. Subcuticular muscles form layer 8-16 $\mu$ thick. Zone containing abundant calcareous corpuscles $48-70 \mu$ thick; corpuscles spherical to ovoid, $6-13 \mu$ in greatest diameter. Muscle bundles of parenchyma strongly developed, $40-45 \mu$ thick. Frontal glands of scolex abundant, diffuse, not extending into body.

Host: Blackfish, Dallia pectoralis Bean.

Habitat: In body cavity of host, unencysted.

Slides containing whole-mounts and sections of plerocercoids have been deposited in the Helminthological Collection of the U. S. National Museum, No. 38118.

\section{Discussion}

The generic term Diphyllobothrium Cobbold, 1858, is taken here to include those species which correspond morphologically to Mueller's (1937) "genus 1". That is to say, the male and female ducts open in a common atrium and the uterine pore opens separately. The "Propulsionblase" is external to the cirrus sac.

The species of Diphyllobothrium are difficult to distinguish, since the adult cestodes show a wide range of morphological variation. The extent of variation is influenced by host-occurrence and other factors, 

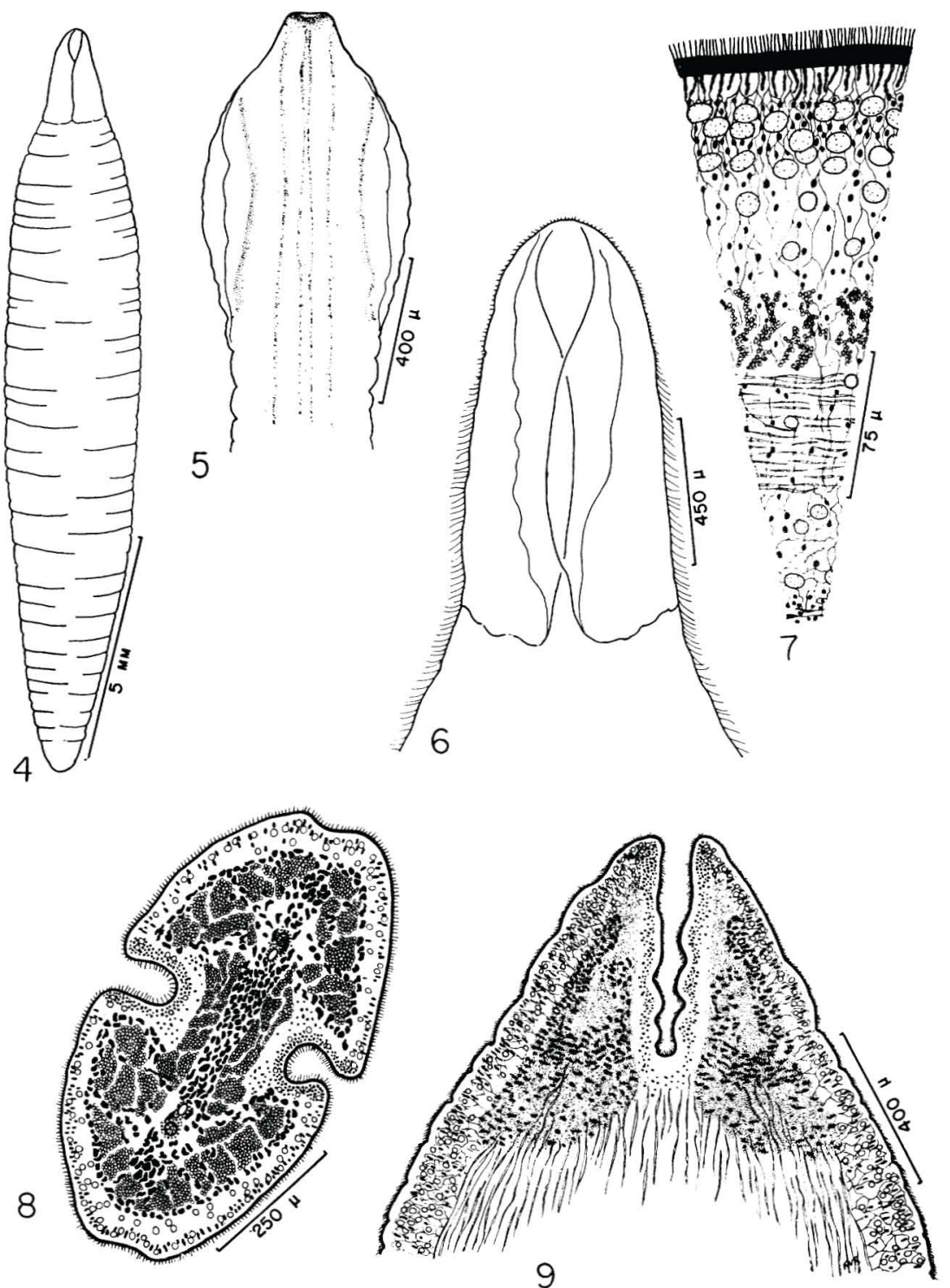

FIG. 4. D. dalliae n. sp., plerocercoid larva from blackfish.

Fig. 5. D. dalliae n. sp., scolex of plerocercoid, lateral view.

FIG. 6. D. dalliae n. sp., scolex of plerocercoid, dorso-ventral view.

FIG. 7. D. dalliae n. sp., segment of cross section through body of plerocercoid.

FIG. 8. D. dalliae n. sp., cross section of scolex of plerocercoid, showing frontal glands.

Fig. 9. D. dalliae n. sp., frontal section through anterior end of plerocercoid, showing froatal glands. 
including crowding (Rausch, 1954). However, species can be characterized through correlation of the adult stage with some of the larval stages, and by the comparative study of strobilae of known age obtained experimentally in various species of host animals. It appears doubtful that it will ever be possible to identify individuals of some species on the basis of the strobilar stage alone when nothing more than the identity of the host is known.

Several recent studies have been concerned with the taxonomic status of species of Diphyllobothrium. Markowski (1949) reviewed the species reported from birds, and concluded that $D$. fissiceps (Creplin, 1829), $D$. cordiceps (Leidy, 1872), D. exile (Linton, 1892), D. canadense Cooper, 1921, D. strictum (Talyzin, 1932), D. laruei Vergeer, 1942, and D. oblongatum Thomas, 1946, are all synonyms of $D$. dendriticum (Nitzsch, 1824).

Kuhlow (1953a) regarded $D$. laruei and $D$. oblongatum together as a species distinct from $D$. dendriticum. Kuhlow also believed that $D$. strictum and $D$. minus Kholodkovskii, 1916, are based on dwarfed forms of D. latum (Linnaeus, 1758).

Both D. minus and $D$. strictum have been studied intensively, particularly on O1'khon Island in Lake Baikal. The findings of Chizhova (1951) indicate that only one species occurs on Ol'khon Island, infecting gulls, dogs, and Man. According to Pavlovskii (1946), the plerocercoid larva of $D$. minus is a small, cylindrical form having an everted scolex, and found encysted on the stomach of Coregonus and Thymallus. Pavlovskii also indicated that the plerocercoids of $D$. minus and $D$. strictum are indistinguishable, and all evidence suggests that the name $D$. strictum has been applied to the primary-type strobila and $D$. minus to the wider, secondary-type strobila of the same species. From available information, D. minus (Syn. D. strictum) must be regarded as being clearly distinct from $D$. latum or $D$. dendriticum.

One or more species closely resembling D. minus occur in North America. Into this group fall $D$. laruei and $D$. oblongatum. The writer has collected similar larvae from Coregonus and Thymallus in arctic Alaska, and has also obtained morphologically similar adults from Alaskan gulls and Man. Some of these species probably have a circumboreal distribution, but their true identity will be established only through future work.

As Stunkard (1949) pointed out, the specific limits of D. latum have not been determined. This name has been applied to almost any large form from Man, but many studies of " $D$. latum" certainly must have been concerned with other species. In the present paper, the morphological details of $D$. dalliae $n$. sp. have been compared with those of $D$. latum as provided by Kuhlow (1953a, 1953b). The plerocercoid of $D$. latum is readily differentiated from those known for other species (Kuhlow, 1953b).

Contrary to Markowski's (1949) view, D. cordiceps appears to be distinct from $D$. dendriticum. Although two or more species have been confused under the name $D$. cordiceps, adult cestodes from bears in Wyoming differ from $D$. dendriticum in several important details (Rausch, 1954).

The recently described $D$. medium (Fahmy, 1954) was based on a single strobila from an otter in Britain. Since comparisons were made with those species of Diphyllobothrium reported from mammalian hosts 
only, and since the material was inadequate, the validity of $D$. medium is questionable.

In order to differentiate species of Diphyllobothrium on the basis of combined larval and adult characteristics, it is necessary to disregard previously described species which have been inadequately characterized. Some of the latter cannot be recognized because of this, but the validity of others may be eventually confirmed. Consequently, $D$. dalliae n. sp. is compared with the following species only:

Gross and histological details of the plerocercoid larva serve to distinguish $D$. dalliae n. sp. from $D$. latum, $D$. osmeri von Linstow, 1878 , $D$. vogeli Kuhlow, 1953, and $D$. ursi Rausch, 1954 . Of these, only $D$. ursi and $D$. osmeri are known to occur in Alaska. The plerocercoid larva of $D$. osmeri is harbored commonly by Osmerus eperlanus dentex Steindachner in the Kuskokwim River.

$D$. dalliae n. sp. may be differentiated from $D$. cordiceps, D. tungussicum Podiapolskaia and Gnedina, 1920, and D. skrjabini Plotnikoff, 1932, ${ }^{1}$ by the distribution of the testes and vitellaria, earlier gravid segments, and small size of eggs (than D. tungussicum or D. skrjabini). The latter two species have not been recognized in Alaska.

Although somewhat similar to $D$. nenzi Petrov, 1938, in the strobilar stage, $D$. dalliae n. sp. differs from this species in anterior extent of the gravid uterus (may encircle the cirrus sac in $D$. nenzi), in the lack of an apical knob on the egg, and in the absence of a long, attenuated anterior region with relatively slow maturation of the genital organs. $D$. nenzi has been recorded only from the Pechora River region east of the Kola Peninsula.

D. dalliae n. sp. may be distinguished from $D$. giljacicum Rutkevich, 1937, and $D$. luxi Rutkevich, 1937, by differences in the size and form of the strobila. Both of the latter are large species with many segments (up to 1830 and 1662, respectively). Fully developed eggs are first seen relatively far back in the strobila, whereas in $D$. dalliae $\mathrm{n}$. $\mathrm{sp}$. they first appear within $30 \mathrm{~mm}$ of the scolex. Both species have been reported only from Sakhalin, and have not been recognized in Alaska. From $D$. cordatum (Leuckart, 1863), D. dalliae n. sp. is differentiated by its much smaller egg, as well as by form of strobila and details of the reproductive organs. It is possible that $D$. cordatum occurs in dogs in Alaska.

The strobilar stages of $D$. dalliae n. sp. and $D$. ditremum Creplin, 1825, are similar. D. dalliae n. sp. differs, however, in that it has larger, less slender eggs which lack an apical knob, much larger testes, and a more rapid rate of maturation. In $D$. dalliae $\mathrm{n}$. sp., the coracidium is spherical and situated in the middle of the egg, whereas in $D$. ditremum it is long-ovoid and situated nearer one end of the egg (Kuhlow, 1953b). $D$. ditremum is mainly a parasite of grebes and other water-birds. Cestodes tentatively identified as $D$. ditremum have been collected by the writer from loons in northern Alaska.

D. dalliae n. $\mathrm{sp}$. resembles $D$. dendriticum in both strobilar and plerocercoid stages. The egg of $D$. dalliae $\mathrm{n}$. $\mathrm{sp}$. is somewhat larger, lacks an apical knob, and the coracidium differs in its position within

${ }^{1}$ In an earlier paper (Rausch, 1954, p. 552), the locality for D. skrjabini was incorrectly given. Nenetskii (Nenets) National Okrug was mistakenly read as Nemetskii (German) National Okrug. 
the egg. The hooks of the embryo are dissimilar. The coracidium is much less motile than that of $D$. dentriticum. The plerocercoid of $D$. dalliae $\mathrm{n}$. sp. differs from that of $D$. dendriticum in the presence of cuticular bristles on the scolex and in histological details. In the strobilar stage, D. dalliae n. sp. possesses larger testes of less restricted distribution at the posterior margin of the segment, a dissimilar distribution of the vitellaria (no free space around the cirrus sac, as seen in $D$. dendriticum) and the gravid uterus does not extend anterior to the cirrus sac. Details of $D$. dendriticum were obtained from Kuhlow (1953c).

Adult cestodes resembling $D$. dendriticum in morphological details have been collected from various species of gulls in Alaska. The plerocercoid has not yet been collected.

Among the plerocercoid larvae of Diphyllobothrium spp. so far observed in Alaskan fishes, that of $D$. dalliae $\mathrm{n}$. sp. is unique in that it occurs free in the body cavity of the host. In the blackfish, the larvae are usually found ventral to the viscera, and are often visible through the abdominal wall. The finding of small larvae in the wall of the stomach must indicate that they enter the body cavity via this organ. Such is the case in other species which usually go no farther than the serosa of the stomach, where they encyst.

At Napaskiak, on the lower Kuskokwim River, 79 percent of the 110 blackfish examined were infected. The number of larvae per fish ranged from 1 to 11 (av. 2.5). At Chevak, farther to the west, 84.4 percent of 45 blackfish were infected, with 1-30 larvae per fish (av. 3.7). Plerocercoids of $D$. dalliae n. sp. from blackfish collected at East Aumalik, in northern Alaska, were sent to the writer by Dr. Norman J. Wilimovsky, Stanford University. In 1949, the writer collected recently ingested larvae of $D$. dalliae n. sp. from an arctic tern, Sterna paradisaea Brünnich, about 60 miles east of Point Barrow.

If the plerocercoid of $D$. dalliae n. sp. is harbored only by the blackfish, its distribution is accordingly restricted to the geographic range of the host. Walters (1955) states that the blackfish is found in Alaska from the Kuskokwim River system north to the Arctic Slope and east to the Ikpikpuk River. In Siberia, it is found on the Chukotskyi Peninsula as far west as the Kolyma River. It has been recorded from St. Lawrence Island, and the writer has collected it on St. Matthew Island, both in the Bering Sea.

The natural final host of $D$. dalliae n. sp. is unknown. Both mink and otter feed heavily upon blackfish in the Kuskokwim River region, but none has been found infected. An attempt to infect a ferret experimentally was unsuccessful. The occurrence of $D$. dalliae $\mathrm{n}$. $\mathrm{sp}$. is to be expected in gulls, and probably in dogs, which are often given blackfish as food in western Alaska. A single sttempt to infect Man experimentally was unsuccessful.

The observations on the coracidium of $D$. dalliae n. sp. included above were provided by Mr. Douglas K. Hilliard, who will report his work in detail at a later date. Mr. Francis S. L. Williamson assisted both in the field and in the laboratory. Mrs. Reggie V. Rausch prepared the histological material and drawings. The writer wishes to express his sincere thanks for this assistance. 


\section{Literature Cited}

Chizhova, T. P. 1951. O Difillobotriidakh chaek na Baikale. Zoö1. Zhur., 30: 217-223.

FAнмy, M. A. M. 1954. On some helminth parasites of the otter, Lutra lutra. J. Helminth., 28: 189-204.

Kunlow, F. 1953a. Beiträge zur Entwicklung und Systematik heimischer Diphyllobothrium-Arten. Zeitschr. Tropenmed. u. Parasit., 4: 203-234.

1953b. Bau und Differentialdiagnose heimischer Diphyllobothrium-Plerocercoide. Zeitschr. Tropenmed. u. Parasit., 4: 186-202.

1953c. Utber die Entwicklung und Anatomie von Diphyllobothrium dendriticum Nitzsch, 1824. Zeitschr. Parasitenk., 16:1-35.

Markowski, S. 1949. On the species of Diphyllobothrium occurring in birds, and their relation to man and other hosts. J. Helminth., 23: 107-126.

Mueller, J. F. 1937. A repartition of the genus Diphyllobothrium. J. Parasit., 23: $308-310$.

Pavlovski, E. N. 1946. Rukovodstvo po parazitologii cheloveka. Vo1. 1, Moscow-Leningrad, $521 \mathrm{pp}$.

Rausch, R. 1954. Studies on the helminth fauna of Alaska. XXI. Taxonomy, morphological variation, and ecology of Diphyllobothrium ursi n. sp. provis. on Kodiak Island. J. Parasit., 40: 540-563.

Stunkard, H. W. 1949. Diphyllobothrium stemmacephalum Cobbold, 1858 and $D$. latum (Linn., 1758). Ibid., 35: 613-624.

Walters, V. 1955. Fishes of western Arctic America and eastern Arctic Siberia. Bull. Amer. Mus. Nat. Hist. 106, Art. 5, pp. 255-368. 